Supplement of

\title{
High-resolution measurements of elemental mercury in surface water for an improved quantitative understanding of the Baltic Sea as a source of atmospheric mercury
}

Joachim Kuss et al.

Correspondence to: Joachim Kuss (joachim.kuss@io-warnemuende.de)

The copyright of individual parts of the supplement might differ from the CC BY 4.0 License. 


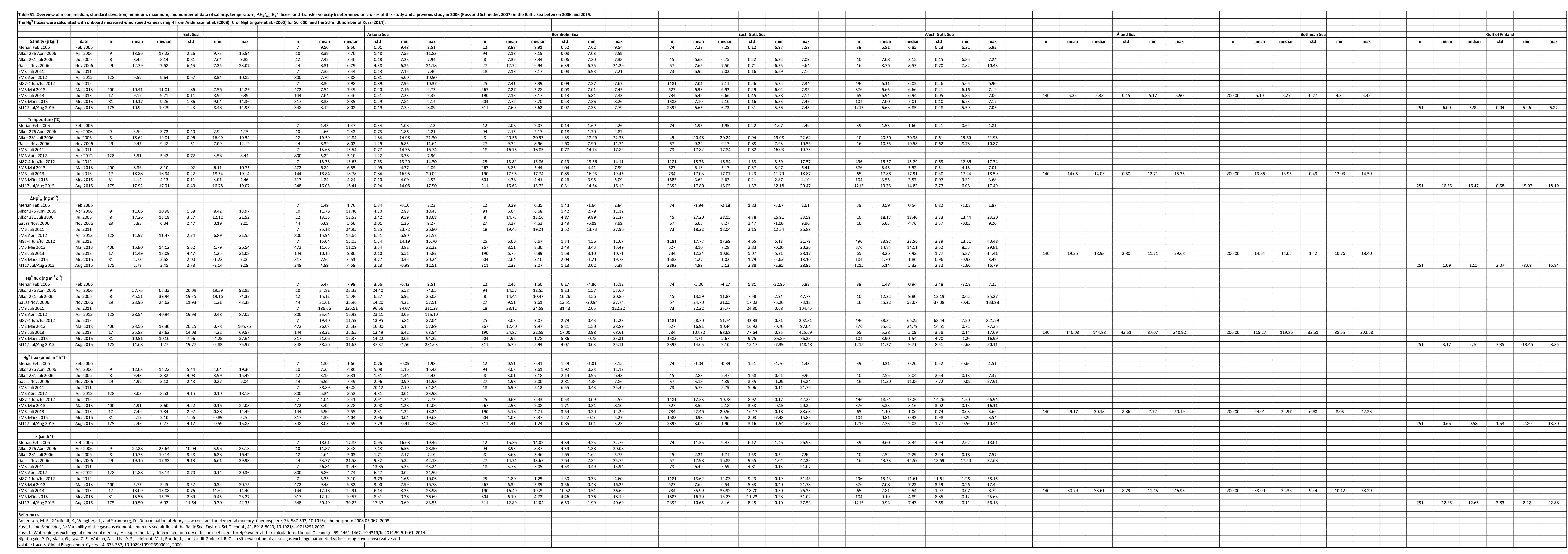




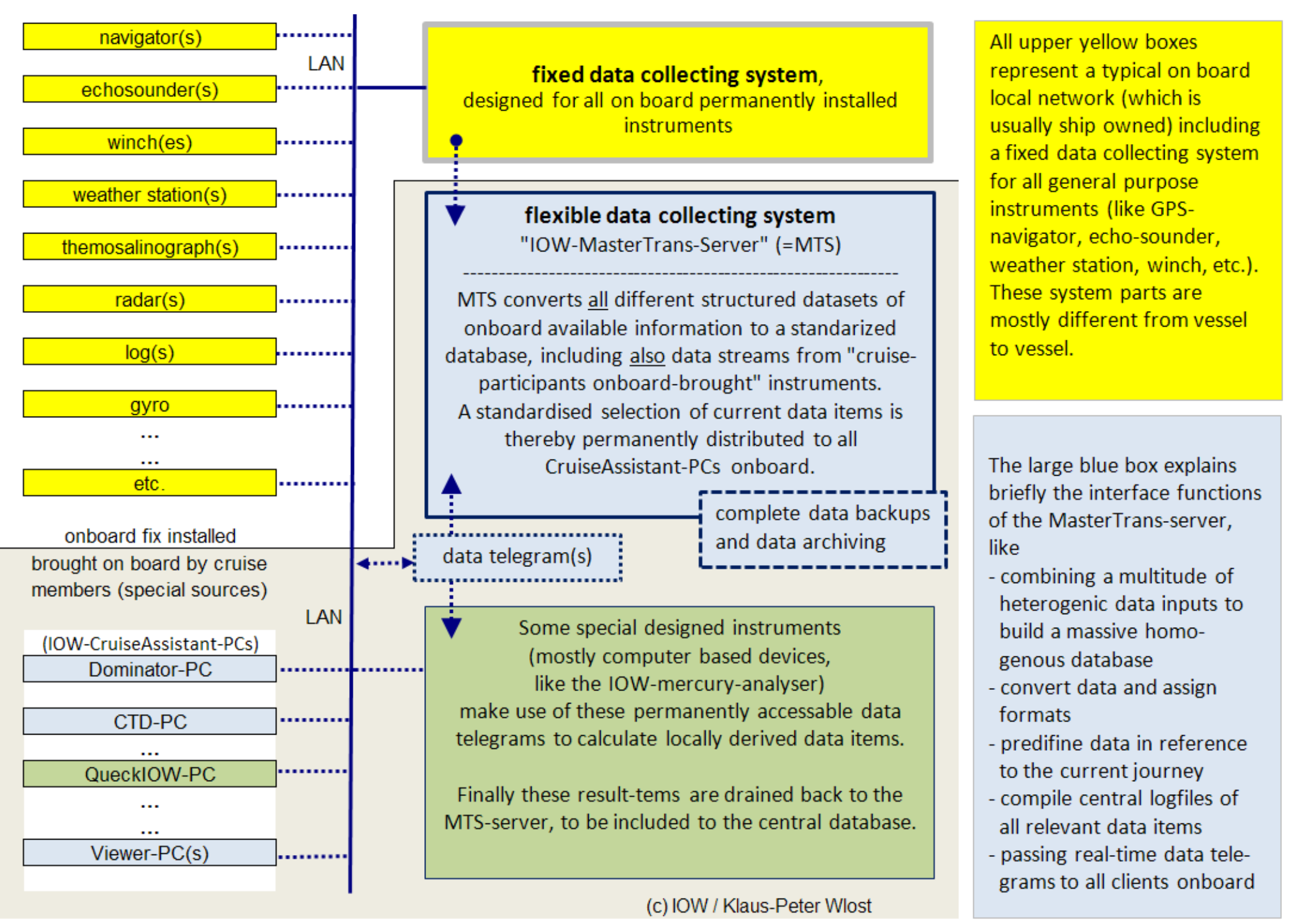

Figure S1: MasterTrans operates as a server based data system that combined data supplied by fixed instrumentation, which are permanently installed onboard the ship, as well as by mobile instruments that are brought on board by cruise participants (i.e., the mercury analyser) to a data telegram, which is then distributed via the ships local area network to all CruiseAssistant client-computers. 